Di ssoci at i ve react i ons i nduced by el ect ron
i mpact and el ectron transport i $n$ TEOS vapor

\begin{tabular}{|l|l|}
\hline 著者 & $\begin{array}{l}\text { KAWAGUCH Sat or u, H GUCH H sashi, LI Hu, } \\
\text { DENPOH Kazuki, TAKAHASH Kazuhi ro, SATOH Kohki }\end{array}$ \\
\hline $\begin{array}{l}\text { j our nal or } \\
\text { publ i cat i on ti tl e }\end{array}$ & Japanese Journal of Appl i ed Physi cs \\
\hline vol une & 58 \\
\hline number & 6 \\
\hline page range & 066003 \\
\hline year & $2019-06-05$ \\
\hline URL & ht t p: //hdl . handl e. net /10258/00009977 \\
\hline
\end{tabular}




\title{
Dissociative reactions induced by electron impact and electron transport in TEOS vapour
}

\author{
Satoru Kawaguchi ${ }^{12^{*}}$, Hisashi Higuchi ${ }^{3^{*}}, \mathrm{Hu} \mathrm{Li}^{3^{*}}$, Kazuki Denpoh ${ }^{3 *}$, Kazuhiro Takahashi ${ }^{1}$, \\ and Kohki Satoh ${ }^{1 *}$ \\ ${ }^{1}$ Division of Information and Electronic Engineering, Graduate School of Muroran Institute \\ of Technology, Muroran, Hokkaido, 050-8585, Japan \\ ${ }^{2}$ Research Fellow of Japan Society for the Promotion of Science \\ ${ }^{3}$ Toyko Electron Technology Solutions Ltd., Nirasaki, Yamanashi, 407-0192, Japan \\ *E-mail: s2124049@mmm.muroran-it.ac.jp, hisashi.higuchi@us.tel.com,hu.li@tel.com, \\ kazuki.denpoh@tel.com,ksatoh@mmm.muroran-it.ac.jp
}

Reactions for dissociative ionization and neutral dissociation collisions between an electron and a tetraethoxysilane $\left[\mathrm{Si}\left(\mathrm{OC}_{2} \mathrm{H}_{5}\right)_{4}, \mathrm{TEOS}\right]$ molecule are reported, and neutral dissociation cross sections are calculated by applying the classical Rice-Ramsperger-Kassel (RRK) theory. Detailed electron collision cross section set of TEOS vapour, including 18 neutral dissociation cross sections and 20 ionization cross sections, is constructed. Electron transport coefficients, such as the mean-arrival-time drift velocity, bulk drift velocity, longitudinal bulk diffusion coefficient, and ionization coefficient, and rate coefficients for both elastic and inelastic collisions in TEOS vapour are calculated from the present cross section set using a Monte Carlo method. The validity of the present cross section set is demonstrated by comparing the calculated electron transport coefficients with measured data. Furthermore, fragmentation of TEOS molecules by electron impact is simulated, and then the number of fragments produced in the simulation is compared with measured mass spectra. 


\section{Introduction}

Plasma enhanced chemical vapour deposition using tetraethoxysilane [ $\mathrm{Si}\left(\mathrm{OC}_{2} \mathrm{H}_{5}\right)_{4}$, TEOS] vapour is a key technology to deposit silicon dioxide $\left(\mathrm{SiO}_{2}\right)$ thin film [1], which works as a dielectric layer in semiconductor devices, such as dynamic random access memory (DRAM) and three-dimensional NAND flash memory [2]. Since the internal structure of the semiconductor devices is complicated, improving uniformity of the deposited film with high deposition rate is required. Therefore, the proper control of the spatial distribution of deposition precursors, which are generated in discharge plasma containing TEOS vapour and contribute to $\mathrm{SiO}_{2}$ deposition, is needed.

Since electron collisions with gas molecules are known to be important processes to generate and maintain discharges, namely to produce species consisting of discharges, electron transport coefficients and rate coefficients for electron collision reactions are useful information on how to handle the discharge plasma so as to properly control the species generated in the discharge. Furthermore, those coefficients allow us to simulate the discharge plasma [3-5]; therefore, reliable and detailed coefficients are highly required. Electron transport coefficients and rate coefficients can be calculated from electron collision cross sections; consequently, reliable and detailed electron collision cross sections of TEOS vapour are needed.

Kawaguchi et al. [6] previously proposed detailed electron collision cross section set of TEOS vapour, which consists of one elastic momentum transfer, two vibrational excitation, one electronic excitation, and 20 ionization cross sections, based on measured ionization cross sections [7], theoretically calculated elastic momentum transfer cross section [8], and estimated cross sections [8,9]. The validity of the proposed cross section set was demonstrated by comparing calculated electron transport coefficients with measured data in TEOS $[10,11]$ and TEOS $/ \mathrm{O}_{2}$ mixtures [12] in a wide range of reduced electric field $E / N$. Here, $E$ and $N$ respectively denote an electric field and the number density of gas molecules. However, since dissociative reactions between an electron and a TEOS molecule are unclear and no neutral dissociation cross sections have been reported, information on neutral species generated by dissociative ionization and neutral dissociation collisions is not included in the proposed cross section set.

Maeda et al. [13] investigated the dissociation of TEOS molecules by electron impact. In their experiment, TEOS molecules were dissociated by an electron beam, and generated fragments were measured by quadrupole mass spectrometer (QMS). They reported measured mass spectra at the electron beam energy of $8,9,15,40$, and $70 \mathrm{eV}$. The mass spectrum of 
TEOS was also reported by NIST Mass Spectrometry Data Center [14]. Holtgrave et al. [7] observed 20 kinds of positive ions generated by electron collisions with TEOS molecules by Fourier-transform mass spectrometry. They provided composition formulae of the observed ions, and this suggests 18 kinds of neutral dissociation reactions which produce neutral molecules with the same stoichiometry of the observed ion species.

Denpoh and Nanbu [15] proposed a method of calculating neutral dissociation cross sections by applying the classical Rice-Ramsperger-Kassel (RRK) theory [16]. They applied their method (hereafter referred to as DN method) to deduce cross sections for neutral dissociation collisions between ions $\left[\mathrm{CF}_{x}^{+}(x=0-3), \mathrm{C}^{+}, \mathrm{F}^{-}\right.$, and $\left.\mathrm{CF}_{3}^{-}\right]$and a $\mathrm{CF}_{4}$ molecule. They firstly calculated the probabilities of neutral dissociation collisions by using the classical RRK theory, and the calculated probabilities were multiplied by a total cross section deduced from the Langevin-Hassé model [17], deducing neutral dissociation cross sections. With such method, the cross sections for neutral dissociation reactions of a TEOS molecule induced by electron impact may also be estimated.

In this work, we report reactions for dissociative ionization and neutral dissociation collisions between an electron and a TEOS molecule deduced from first-principle quantum mechanical simulation based on the density function theory with Gaussian09 package $[18,19]$, and then electron collision cross sections for neutral dissociations of a TEOS molecule are calculated by applying DN method. The information concerning the dissociative collisions is added to the cross section set reported by Kawaguchi et al. [6], constructing a detailed cross section set of TEOS vapour. The mean-arrival-time drift velocity, bulk drift velocity, longitudinal bulk diffusion coefficient, and rate coefficients for both elastic and inelastic electron collisions in TEOS vapour are calculated from the present cross section set using the Monte Carlo method. The validity of the present cross section set is demonstrated by comparing calculated and measured electron transport coefficients. Furthermore, fragmentation of TEOS molecules by electron impact is simulated using the present cross section set, and then the number of fragments produced in the simulation is compared with the measured mass spectra reported by Maeda et al. [13]

\section{Present cross section set of TEOS vapour}

Table 1 shows the reactions between an electron and a TEOS molecule for elastic momentum transfer (mom), vibrational excitation (vib1, vib2), non-dissociative electronic excitation (non-diss-ex), neutral dissociation (nd1 - nd18), and ionization (i1 - i20) collisions considered in this work. Description of the dissociative reactions shown in table 1 is given 
in Ref. 19. The threshold energies of ionization collisions are taken from ion appearance energies reported by Holtgrave et al. [7]. Figure 1 shows electron collision cross sections for the reactions shown in table 1 as a function of electron energy $\varepsilon$. Here, $\Sigma q_{\text {nd }}$ and $\Sigma q_{\text {i }}$ denote the sum of neutral dissociation and ionization cross sections, respectively, and the partial cross sections for neutral dissociation collisions are shown in Fig. 2. The elastic momentum transfer, vibrational excitation, and ionization cross sections previously proposed by Kawaguchi et al.[6] are used, but the shape of the vibrational excitation cross sections is slightly modified.

Neutral dissociation cross sections and non-dissociative electronic excitation cross sections are calculated by applying DN method, the details of which are described in Ref. 15. Briefly, the method assumes that a colliding pair called reactants, an electron and a TEOS molecule in this work, forms an activated complex, and then the autodecomposition of the complex generates products or reproduces reactants. Under such assumption, the rate of generating products $k_{r-i}$ and reproducing the reactants $k_{\mathrm{el}}$ can be calculated by using the classical RRK theory as follows:

$$
\begin{gathered}
k_{r-i}(\varepsilon)=\bar{v}\left(\frac{\varepsilon-\Delta E_{i}}{V}\right)^{s-1}, \\
k_{e l}(\varepsilon)=\bar{v}\left(\frac{\varepsilon}{V}\right)^{s-1},
\end{gathered}
$$

where $\bar{v}$ and $s$ are respectively the mean frequency for vibration and the number of vibrational modes of the complex, $\Delta E_{i}$ is the differential energy between reactants and products in the ground state, and $V$ is the total energy measured from the ground state of the complex. In general, $s=a\left(3 N_{a}-6\right)$, where $N_{a}$ is the number of atoms in a TEOS molecule, and $a$ is an adjustable factor of $1 / 4-2 / 3$. In this work, we assume $a=1 / 4$. The molecular structures of the products generated in each reaction $i$ are studied by Gaussian09 package using $\mathrm{B} 3 \mathrm{LYP} / 6-311+\mathrm{G}(2 \mathrm{~d}, \mathrm{p})$ [18-22], and then $\Delta E_{i}$ are calculated. Probabilities of generating products $P_{r-i}$ and reproducing reactants $P_{\mathrm{el}}$ are defined as

$$
\begin{gathered}
P_{r-i}(\varepsilon)=\frac{k_{r-i}(\varepsilon)}{k_{e l}(\epsilon)+\sum_{i=1}^{18} k_{r-i}(\varepsilon)^{\prime}} \\
P_{e l}(\varepsilon)=\frac{k_{e l}(\varepsilon)}{k_{e l}(\varepsilon)+\sum_{i=1}^{18} k_{r-i}(\varepsilon)} .
\end{gathered}
$$

Values of $\bar{v}$ and $V$ are canceled in Eqs. (3) and (4). In this work, reproducing the reactants is specified as non-dissociative electronic excitation. Neutral dissociation cross sections $q_{\text {nd- }}$ $i$, and non-dissociative electronic excitation cross section $q_{\text {non-diss-ex }}$ are calculated by dividing total excitation cross sections, namely the sum of vibrational excitation $q_{\mathrm{vib}}$ and the electronic excitation $q_{\text {ex }}$ cross sections, using calculated probabilities as 


$$
\begin{gathered}
q_{\mathrm{nd}-i}(\varepsilon)=\left[\sum q_{\mathrm{vib}}(\varepsilon)+q_{\mathrm{ex}}(\varepsilon)\right] P_{r-i}(\varepsilon), \\
q_{\mathrm{non}-\mathrm{diss}-\mathrm{ex}}(\varepsilon)=\left[\sum q_{\mathrm{vib}}(\varepsilon)+q_{\mathrm{ex}}(\varepsilon)\right] P_{e l}(\varepsilon)-\sum q_{\mathrm{vib}}(\varepsilon),
\end{gathered}
$$

where $\Sigma q_{\text {vib }}$ denotes the sum of $q_{\text {vib. }}$. Here, $q_{\text {ex }}$ previously proposed by Kawaguchi et al. [6] is used, but its shape is slightly modified. Since $P_{\text {el }}$ is almost equal to 1 , the shape of $q_{\text {non-diss- }}$ ex is almost the same as that of $q_{\text {ex }}$ below $30 \mathrm{eV}$.

\section{Simulation method and conditions}

\subsection{Electron transport analysis in TEOS vapour}

The behaviour of electrons in TEOS vapour under a uniform DC electric field is simulated by the Monte Carlo method. No boundary is considered in the simulation. The mean-arrivaltime drift velocity $W_{\mathrm{m}}$, bulk drift velocity $W_{\mathrm{r}}$ also referred to as the center-of-mass drift velocity, longitudinal bulk diffusion coefficient $N D_{\mathrm{L}}$, ionization coefficient $\alpha / N$, and rate coefficients $k$ for both elastic and inelastic collisions are deduced by sampling. The rate coefficients for $l$ th reaction $k_{l}$ are sampled as

$$
k_{l}(t)=\frac{1}{N_{\mathrm{e}}(t)} \sum_{i=1}^{N_{\mathrm{e}}(t)} q_{l}\left(\varepsilon_{i}\right) \sqrt{2 q \varepsilon_{i} / m_{\mathrm{e}}}
$$

where $q$ and $m_{\mathrm{e}}$ are the charge and mass of a electron, respectively, $N_{\mathrm{e}}(t)$ is the number of electrons at time $t, \varepsilon_{i}$ is the energy of $i$ th electron, and $q_{l}\left(\varepsilon_{i}\right)$ is electron collision cross sections for $l$ th reaction at $\varepsilon_{i}$. Sampling principles of the electron transport coefficients are described by Kawaguchi et al. [23, 24]. Collisions between an electron and a TEOS molecule are only considered, assuming typical condition of the electron swarm experiment. Thermal motion of TEOS molecules, which may affect the electron transport coefficients under low $E / N$, are considered by the same method described by Yousfi et al. [25], and electron scattering is assumed to be isotropic because of a lack of data on differential cross sections. The number density of gas molecules $N$ is assumed to be $3.535 \times 10^{16} \mathrm{~cm}^{-3}\left(0^{\circ} \mathrm{C}, 133.32 \mathrm{~Pa}\right)$. Numerical techniques of the simulation are shown in Refs. $[23,24,26]$ in detail.

\subsection{Simulation for the fragmentation of TEOS molecules by electron impact}

Fragmentation of TEOS molecules by electron impact in an ionization chamber of a mass spectrometer is simulated. The ionization chamber is known to comprise a filament at the center and a coaxial cylindrical electrode at the outside. In the ionization chamber, electrons emitted from the filament accelerate by an electric field, collide gas molecules, and then 
reach to the cylindrical electrode. The strength of the electric field $E$ generated between the filament and the cylindrical electrode is expressed as

$$
E(r)=\frac{V_{g}}{\ln \left(R / r_{0}\right)} \frac{1}{r}
$$

where $r_{0}$ and $R$ are respectively the radius of the filament and the cylindrical electrode, $r$ is the distance from the filament, and $V_{g}$ is the electric potential difference between the filament and the cylindrical electrode. Since the gas pressure in the ionization chamber is generally quite low, the emitted electrons are accelerated rapidly in the vicinity of the filament, and most of them become energetic before the collision; therefore, for the sake of simplicity, the ionization chamber is assumed to comprise two infinite parallel plates $P_{1}(z=$ $0)$ and $P_{2}(\mathrm{z}=d)$, and initial electrons emitted from the plate $P_{1}$ having initial velocity $\left(0,0, \sqrt{2 q \epsilon_{0} / m_{\mathrm{e}}}\right)$ are traced under no electric field by using a Monte Carlo method until all initial electrons are reached at the plates. Here, $\epsilon_{0}$ is initial energy of electrons, $d$ is the gap length between the plates, and $d$ is set to $30 \mathrm{~mm}$. Reflection of the electrons on the plates is not considered. In the fragmentation simulation, $N$ is set to $2.651 \times 10^{11} \mathrm{~cm}^{-3}\left(0^{\circ} \mathrm{C}, 10^{-3}\right.$ $\mathrm{Pa}$ ), which is almost equivalent to the experimental condition reported by Maeda et al. [13]

The number of fragments produced by electron collisions with TEOS molecules is counted in the simulation. Since little information on electron collision cross sections of fragments is reported as of now, collisions between an electron and fragments are not considered, and all neutral fragments produced in the simulation are assumed to be fully ionized in the ionization chamber. Under such assumption, the number of fragments is proportional to their intensities measured by the mass spectrometer.

\section{Results and discussion}

\subsection{Electron transport coefficients in TEOS vapour}

Figures 3(a) and 3(b) show values of the ionization coefficient $\alpha / N$ and longitudinal bulk diffusion coefficient $N D_{\mathrm{L}}$ in TEOS vapour calculated from the present cross section set as functions of $E / N$. Those measured by double-shutter drift tube method [10] and steady-state Townsend experiment [11] are also shown in Figs. 3(a) and 3(b). The calculated values of $\alpha / N$ and $N D_{\mathrm{L}}$ well reproduce the measured data in a wide range of $E / N$. Figure 4 shows electron energy distribution in TEOS vapour at $6,000 \mathrm{Td}$, which is the highest $E / N$ value studied here. This indicates that most electrons are distributed below $30 \mathrm{eV}$, where the magnitude of $q_{\text {nd- } i}$ is too small to affect electron transport coefficients and cross sections, except for $q_{\mathrm{nd}-i}$, are almost the same as those reported by Kawaguchi et al. [6]; therefore, 
calculated electron transport coefficients are found to be almost the same as those previously reported [6].

Figure 3(c) shows values of the mean-arrival-time drift velocity $W_{\mathrm{m}}$ and bulk drift velocity $W_{\mathrm{r}}$ calculated from the present cross section set as a function of $E / N$. It is known that values of electron drift velocity may vary with its definition when ionization and/or electron attachment collisions occur [27-30], and the relation between $W_{\mathrm{r}}$ and $W_{\mathrm{m}}$ is described as [30]

$$
W_{r}=W_{m}+2(\alpha-\eta) D_{L}-3(\alpha-\eta)^{2} D_{3}+\cdots,
$$

where $\eta$ is the electron attachment coefficient, which is nought in TEOS vapour, and $D_{3}$ is the longitudinal third-order transport coefficient; therefore, the values of $W_{\mathrm{r}}$ are equal to those of $W_{\mathrm{m}}$ below $450 \mathrm{Td}$, where the values of $\alpha$ are nought or quite small, and then tend to be higher than those of $W_{\mathrm{m}}$ with increasing values of $E / N$. One should heed that the continuity of the number density of electrons in plasmas is traditionally described by using the effective ionization collision frequency, $W_{\mathrm{r}}$ instead of $W_{\mathrm{m}}$, and $D_{\mathrm{L}}[30,31]$. To compare the calculated values of the electron drift velocity with measured data, values of the electron drift velocity measured by double-shutter drift tube method [10], which are known to be equal to $W_{\mathrm{m}}[30]$, are also shown in Fig. 3(c). Good agreement between the calculated values of $W_{\mathrm{m}}$ and the measured data is found.

The calculated values of the ionization coefficient $\alpha / N$, longitudinal bulk diffusion coefficient $N D_{\mathrm{L}}$, and mean-arrival-time drift velocity $W_{\mathrm{m}}$ in TEOS vapour are found to well reproduce the measured data in a wide range of $E / N$. This indicates the validity of the present cross section set.

\subsection{Comparison between calculated number of fragments with measured mass spectra}

Maeda et al. [13] mentioned that a TEOS molecule dissociates by electron impact at an electron energy below $7 \mathrm{eV}$, although in the fragmentation simulation fragments are generated at an initial electron energy above $10 \mathrm{eV}$. Figure 5 shows the number of fragments generated in the fragmentation simulation as functions of mass number of fragments $m$, together with measured mass spectra reported by Maeda et al. [13]. Here, the number of fragments is normalized such that the number of $\mathrm{Si}\left(\mathrm{OC}_{2} \mathrm{H}_{5}\right)_{2} \mathrm{OCH}_{3}(m=149)$ agrees with its measured intensity. The normalized number of $\mathrm{CH}_{3}(m=15), \mathrm{C}_{2} \mathrm{H}_{4}(m=28), \mathrm{OC}_{2} \mathrm{H}_{4}(m=$ $44), \mathrm{OC}_{2} \mathrm{H}_{5}+\mathrm{Si}(\mathrm{OH})+\mathrm{OC}_{2} \mathrm{H}_{5}{ }^{+}+\mathrm{SiOH}^{+}(m=45)$ are outside of the range on the vertical axes, so that those numbers are written in the figure. It is found that the simulation results 
broadly reproduce the measured mass spectra, indicating that the dissociative reactions and dissociative cross sections, neutral dissociation and dissociative ionization cross sections, used in the simulation are valid to a certain extent. Differences between the simulation results and measured mass spectra appear at $m=15,28,44$, and 45 . This may be caused by the dissociative reactions and/or the dissociative cross sections used in the simulation. In this work, the dissociative reactions are chosen such that the potentials of non-silicon containing neutral fragments are minimum; therefore, other dissociative reactions may be possible. Furthermore, considering that ionization cross sections of the neutral fragments depend on their chemical structure and electron energy, the assumption that the neutral fragments generated in the simulation are fully ionized may also lead to the differences; therefore, data on ionization cross sections of the neutral fragments are needed for further investigation of the validity of the dissociative reactions and cross sections. Thus, no attempt to modify the dissociative reactions and cross sections shown above has been done.

\subsection{Rate coefficients for electron collisions with TEOS molecules}

Figure 6 shows values of the rate coefficients for both elastic and inelastic electron collisions with TEOS molecules calculated from the present cross sections as a function of $E / N$. Here, $\Sigma k_{\text {nd }}$ and $\Sigma k_{\text {i }}$ denote the sum of the rate coefficients for neutral dissociation and ionization collisions, respectively, and those rate coefficients are shown in Figs. 7 and 8 in detail. This is the first report on the rate coefficients for reactions between an electron and a TEOS molecule, and the results in this report allow us to model the continuity of electrons, generation of fragments, and conservation of momentum of electrons in the plasma, which are generally considered in the plasma simulations.

\section{Conclusions}

Dissociative reactions between an electron and a TEOS molecule deduced from firstprinciple quantum mechanical simulation are reported, and neutral dissociation cross sections of TEOS vapour are calculated by applying DN method. After that, detailed electron collision cross section set of TEOS vapour are constructed. The present cross section set includes 18 kinds of neutral dissociation cross sections and 20 kinds of ionization cross sections. Values of the ionization coefficient $\alpha / N$, longitudinal bulk diffusion coefficient $N D_{\mathrm{L}}$, mean-arrival-time drift velocity $W_{\mathrm{m}}$, bulk drift velocity $W_{\mathrm{r}}$, and rate coefficients for both elastic and inelastic collisions are calculated from the present cross section set up to 6,000 Td by Monte Carlo method. The validity of the present cross section set is demonstrated by 
comparing between calculated and measured $\alpha / N, N D_{\mathrm{L}}$, and $W_{\mathrm{m}}$. Furthermore, fragmentation of TEOS molecules by electron impact is simulated, and the number of fragments produced in the simulation is compared with the measured mass spectra reported by Maeda et al. The comparison shows the validity of the dissociative reactions and dissociative cross sections reported in this work to a certain extent.

Finally, the data reported in this paper enable us to simulate detailed gas phase reactions in TEOS based plasma, which contain generation reactions of TEOS fragments. The information concerning kinds of TEOS fragments and those amounts can be used for simulation of $\mathrm{SiO}_{2}$ deposition, which includes both gas phase and surface reactions. Those computational studies will give us valuable information to reveal deposition precursors generated in TEOS based plasma and to understand $\mathrm{SiO}_{2}$ deposition mechanism.

\section{Acknowledgments}

This work was supported by Tokyo Electron Ltd. 


\section{References}

1) M. A. Lieberman and A. J. Lichtenberg, Principles of Plasma Discharges and Materials Processing (Wiley, Hoboken, 2005) Chap. 16.

2) T. Ichikawa, D. Ichinose, and N. Tamaoki, Toshiba Review, 66, 29 (2011) [in Japanese].

3) T. Makabe and Z. Lj. Petrovic, Plasma Electronics: Applications in Microelectronic Device Fabrication (CRC Press, Boca Raton, 2015) 2nd ed., Chap. 7.

4) M. J. Kushner, J. Phys. D: Appl. Phys. 42, 194013 (2009).

5) R. E. Robson, R. D. White, and Z. Lj. Petrović, Rev. Mod. Phys. 77, 1303 (2005).

6) S. Kawaguchi, K. Takahashi, K. Satoh, and H. Itoh, Plasma Sources Sci. Technol. 26, 054001 (2017) [Erratum 27, 079601 (2018)].

7) J. Holtgrave, K. Riehl, D. Abner, and P. D. Haaland, Chem. Phys. Lett. 215, 548 (1993).

8) W. L. Morgan, C. Winstead, and V. McKoy, J. Appl. Phys. 92, 1663 (2002).

9) D. A. Tuan, B. H. Jeon, J. Phys. Soc. Japan 81, 064301 (2012).

10) K. Yoshida, T. Ohshima, H. Ohuchi, Y. Kishimoto, and H. Tagashira, J. Phys. D: Appl. Phys. 29, 2447 (1996).

11) K. Yoshida, T. Ohshima, H. Ohuchi, and H. Tagashira, J. Phys. D: Appl. Phys. 28, 2478 (1995).

12) K. Yoshida, H. Tagashira, T. Ohshima, H. Ohuchi, and Y. Kishimoto, J. Phys. D: Appl. Phys. 29, 2124 (1996).

13) N. Maeda, K. Okimura, and A. Shibata, Denki Gakkai Ronbunshi A 117, 852 (1997) [in Japanese]

14) NIST Mass Spectrometry Data Center, S.E. Stein, director, "Mass Spectra" in NIST Chemistry WebBook NIST Standard Reference Database Number 69, Eds. P.J. Linstrom and W.G. Mallard, National Institute of Standards and Technology, Gaithersburg MD, 20899, doi:10.18434.T4D303 (retrieved March 16, 2017).

15) K. Denpoh and K. Nanbu, J. Vac. Sci. Technol. A 16, 1201 (1998).

16) J. I. Steinfeld, J. S. Francisco, and W. L. Hase, "Chemical Kinetics and Dynamics" (Tokyo Kagaku Doujin, Tokyo, 1995), Japanese ed., Chap. 11.

17) K. Nanbu and Y. Kitatani, J. Phys. D: Appl. Phys. 28, 324 (1995).

18) M. J. Frisch, G. W. Trucks, H. B. Schlegel, G. E. Scuseria, M. A. Robb, J. R. Cheeseman, G. Scalmani, V. Barone, G. A. Petersson, H. Nakatsuji, X. Li, M. Caricato, A. Marenich, J. Bloino, B. G. Janesko, R. Gomperts, B. Mennucci, H. P. Hratchian, J. V. Ortiz, A. F. Izmaylov, J. L. Sonnenberg, D. Williams-Young, F. Ding, F. Lipparini, F. Egidi, J. Goings, B. Peng, A. Petrone, T. Henderson, D. Ranasinghe, V. G. Zakrzewski, J. Gao, N. Rega, G. 
Zheng, W. Liang, M. Hada, M. Ehara, K. Toyota, R. Fukuda, J. Hasegawa, M. Ishida, T. Nakajima, Y. Honda, O. Kitao, H. Nakai, T. Vreven, K. Throssell, J. A. Montgomery, Jr., J. E. Peralta, F. Ogliaro, M. Bearpark, J. J. Heyd, E. Brothers, K. N. Kudin, V. N. Staroverov, T. Keith, R. Kobayashi, J. Normand, K. Raghavachari, A. Rendell, J. C. Burant, S. S. Iyengar, J. Tomasi, M. Cossi, J. M. Millam, M. Klene, C. Adamo, R. Cammi, J. W. Ochterski, R. L. Martin, K. Morokuma, O. Farkas, J. B. Foresman, and D. J. Fox, Gaussian 09 (Gaussian, Inc., Wallingford CT, 2016).

19) H. Li, H. Higuchi, S. Kawaguchi, K. Satoh, and K. Denpoh: in preparation for publication. 20) A. D. Becke: J. Chem. Phys. 98, 5648 (1993).

21) A. D. McLean and G. S. Chandler: J. Chem. Phys. 72, 5639 (1980).

22) K. Raghavachari, J. S. Binkley, R. Seeger, and J. A. Pople: J. Chem. Phys. 72, 650 (1980).

23) S. Kawaguchi, K. Satoh, and H. Itoh, Eur. Phys. J. D 68, 100 (2014).

24) S. Kawaguchi, K. Satoh, and H. Itoh, Japan. J. Appl. Phys. 54, 01 AC01 (2015).

25) M. Yousfi, A. Hennad, and A. Alkaa, Phys. Rev. E 49, 3264 (1994).

26) S. Kawaguchi, K. Takahashi, K. Satoh, and H. Itoh, Japan. J. Appl. Phys. 55, 07LD03 (2016).

27) H. Tagashira, Y. Sakai, and S. Sakamoto, J. Phys. D: Appl. Phys. 10, 1051 (1977).

28) K. Satoh, Y. Ohmori, Y. Sakai, and H. Tagashira, J. Phys. D: Appl. Phys. 24, 1354 (1991).

29) K. Satoh, M. Hataguchi, H. Itoh, Y. Sakai, and H. Tagashira, J. Phys. D: Appl. Phys. 27, 1480 (1994).

30) K. Kondo and H. Tagashira, J. Phys. D: Appl. Phys. 23, 1175 (1990).

31) Z. Lj. Petrović, S. Dujko, D. Marić, G. Malović, Ž. Nikitović, O. Šašić, J. Jovanović, V. Stojanović, and M. Radmilović-Rađenović, J. Phys. D: Appl. Phys. 42, 194002 (2009). 


\section{Figure Captions}

Fig. 1. (Color online) Electron collision cross section set of TEOS vapour.

Fig. 2. (Color online) Neutral dissociation cross sections of TEOS vapour as functions of electron energy $\varepsilon$. (a) nd1 - nd3, (b) nd4 - nd7, (c) nd8 - nd10, (d) nd11, nd12, (e) nd13 - nd16, and (f) nd17, nd18.

Fig. 3. (Color online) Electron transport coefficients in TEOS vapour as functions of reduced electric field $E / N$. (a) Ionization coefficient, (b) Longitudinal bulk diffusion coefficient, and (c) Electron drift velocity.

Fig. 4. (Color online) Electron energy distribution in TEOS vapour at 6,000 Td.

Fig. 5. (Color online) Comparison between calculated number of fragments and measured mass spectra. (a) $\varepsilon_{0}=15 \mathrm{eV}$, (b) $\varepsilon_{0}=40 \mathrm{eV}$, and (c) $\varepsilon_{0}=70 \mathrm{eV}$.

Fig. 6. (Color online) Rate coefficients for elastic and inelastic collisions in TEOS vapour as a function of $E / N$.

Fig. 7. (Color online) Rate coefficients for neutral dissociation collisions in TEOS vapour as functions of $E / N$. (a) nd1 - nd3, (b) nd4 - nd7, (c) nd8 - nd10, (d) nd11, nd12, (e) nd13 - nd16, and (f) nd17, nd18.

Fig. 8. (Color online) Rate coefficients for ionization collisions in TEOS vapour as functions of $E / N$. (a) i1 - i5, (b) i6 - i10, (c) i11 - i15, and (d) i16 - i20 
Table I. Reactions for collisions between an electron and a TEOS molecule and their threshold energies $\Delta E_{i}$.

\begin{tabular}{|c|c|c|}
\hline Label & Reaction & $\begin{array}{c}\Delta E_{i} \\
(\mathrm{eV})\end{array}$ \\
\hline mom & $\mathrm{Si}\left(\mathrm{OC}_{2} \mathrm{H}_{5}\right)_{4}+\mathrm{e} \rightarrow \mathrm{Si}\left(\mathrm{OC}_{2} \mathrm{H}_{5}\right)_{4}+\mathrm{e}$ & \\
\hline vib1 & $\mathrm{Si}\left(\mathrm{OC}_{2} \mathrm{H}_{5}\right)_{4}+\mathrm{e} \rightarrow \mathrm{Si}\left(\mathrm{OC}_{2} \mathrm{H}_{5}\right)_{4}\left(v^{\prime}\right)+\mathrm{e}$ & 0.160 \\
\hline vib2 & $\mathrm{Si}\left(\mathrm{OC}_{2} \mathrm{H}_{5}\right)_{4}+\mathrm{e} \rightarrow \mathrm{Si}\left(\mathrm{OC}_{2} \mathrm{H}_{5}\right)_{4}\left(v^{\prime \prime}\right)+\mathrm{e}$ & 0.370 \\
\hline $\begin{array}{c}\text { non- } \\
\text { diss-ex }\end{array}$ & $\mathrm{Si}\left(\mathrm{OC}_{2} \mathrm{H}_{5}\right)_{4}+\mathrm{e} \rightarrow \mathrm{Si}\left(\mathrm{OC}_{2} \mathrm{H}_{5}\right)_{4} *+\mathrm{e}$ & 7.000 \\
\hline nd1 & $\mathrm{Si}\left(\mathrm{OC}_{2} \mathrm{H}_{5}\right)_{4}+\mathrm{e} \rightarrow \mathrm{Si}\left(\mathrm{OC}_{2} \mathrm{H}_{5}\right)\left(\mathrm{OCH}_{2}\right) \mathrm{H}_{2}+2 \mathrm{OC}_{2} \mathrm{H}_{4}+\mathrm{CH}_{3}+\mathrm{e}$ & 6.515 \\
\hline nd2 & $\mathrm{Si}\left(\mathrm{OC}_{2} \mathrm{H}_{5}\right)_{4}+\mathrm{e} \rightarrow \mathrm{Si}\left(\mathrm{OC}_{2} \mathrm{H}_{5}\right)_{3} \mathrm{O}+\mathrm{C}_{2} \mathrm{H}_{5}+\mathrm{e}$ & 3.726 \\
\hline nd3 & $\mathrm{Si}\left(\mathrm{OC}_{2} \mathrm{H}_{5}\right)_{4}+\mathrm{e} \rightarrow \mathrm{Si}\left(\mathrm{OC}_{2} \mathrm{H}_{5}\right)_{3} \mathrm{OC}_{2} \mathrm{H}_{4}+\mathrm{H}+\mathrm{e}$ & 4.242 \\
\hline nd4 & $\mathrm{Si}\left(\mathrm{OC}_{2} \mathrm{H}_{5}\right)_{4}+\mathrm{e} \rightarrow \mathrm{Si}\left(\mathrm{OC}_{2} \mathrm{H}_{5}\right)_{2} \mathrm{OOH}+\mathrm{C}_{2} \mathrm{H}_{4}+\mathrm{C}_{2} \mathrm{H}_{5}+\mathrm{e}$ & 4.129 \\
\hline nd5 & $\mathrm{Si}\left(\mathrm{OC}_{2} \mathrm{H}_{5}\right)_{4}+\mathrm{e} \rightarrow \mathrm{Si}\left(\mathrm{OC}_{2} \mathrm{H}_{5}\right)_{3}+\mathrm{OC}_{2} \mathrm{H}_{5}+\mathrm{e}$ & 4.446 \\
\hline nd6 & $\mathrm{Si}\left(\mathrm{OC}_{2} \mathrm{H}_{5}\right)_{4}+\mathrm{e} \rightarrow \mathrm{Si}\left(\mathrm{OC}_{2} \mathrm{H}_{5}\right)_{3} \mathrm{OCH}_{2}+\mathrm{CH}_{3}+\mathrm{e}$ & 3.430 \\
\hline nd7 & $\mathrm{Si}\left(\mathrm{OC}_{2} \mathrm{H}_{5}\right)_{4}+\mathrm{e} \rightarrow \mathrm{Si}\left(\mathrm{OC}_{2} \mathrm{H}_{5}\right)_{2}(\mathrm{OH})+\mathrm{C}_{2} \mathrm{H}_{4}+\mathrm{OC}_{2} \mathrm{H}_{5}+\mathrm{e}$ & 4.861 \\
\hline $\mathrm{nd} 8$ & $\mathrm{Si}\left(\mathrm{OC}_{2} \mathrm{H}_{5}\right)_{4}+\mathrm{e} \rightarrow \mathrm{OCH}_{3}+\mathrm{Si}\left(\mathrm{OC}_{2} \mathrm{H}_{5}\right)_{3} \mathrm{CH}_{2}+\mathrm{e}$ & 4.670 \\
\hline nd9 & $\mathrm{Si}\left(\mathrm{OC}_{2} \mathrm{H}_{5}\right)_{4}+\mathrm{e} \rightarrow \mathrm{Si}\left(\mathrm{OC}_{2} \mathrm{H}_{5}\right)\left(\mathrm{OCH}_{2}\right)(\mathrm{OH})_{2}+2 \mathrm{C}_{2} \mathrm{H}_{4}+\mathrm{CH}_{3}+\mathrm{e}$ & 4.262 \\
\hline nd10 & $\mathrm{Si}\left(\mathrm{OC}_{2} \mathrm{H}_{5}\right)_{4}+\mathrm{e} \rightarrow \mathrm{Si}\left(\mathrm{OC}_{2} \mathrm{H}_{5}\right)_{2}(\mathrm{OH})\left(\mathrm{OCH}_{2}\right)+\mathrm{C}_{2} \mathrm{H}_{4}+\mathrm{CH}_{3}+\mathrm{e}$ & 3.844 \\
\hline nd11 & $\mathrm{Si}\left(\mathrm{OC}_{2} \mathrm{H}_{5}\right)_{4}+\mathrm{e} \rightarrow \mathrm{Si}\left(\mathrm{OC}_{2} \mathrm{H}_{5}\right)_{2}\left(\mathrm{OCH}_{2}\right) \mathrm{H}+\mathrm{OC}_{2} \mathrm{H}_{4}+\mathrm{CH}_{3}+\mathrm{e}$ & 4.983 \\
\hline nd12 & $\mathrm{Si}\left(\mathrm{OC}_{2} \mathrm{H}_{5}\right)_{4}+\mathrm{e} \rightarrow \mathrm{Si}\left(\mathrm{OC}_{2} \mathrm{H}_{5}\right)\left(\mathrm{OCH}_{2}\right)(\mathrm{OH}) \mathrm{H}+\mathrm{OC}_{2} \mathrm{H}_{4}+\mathrm{C}_{2} \mathrm{H}_{4}+\mathrm{CH}_{3}+\mathrm{e}$ & 5.343 \\
\hline nd13 & $\mathrm{Si}\left(\mathrm{OC}_{2} \mathrm{H}_{5}\right)_{4}+\mathrm{e} \rightarrow \mathrm{Si}\left(\mathrm{OC}_{2} \mathrm{H}_{5}\right)(\mathrm{OH})_{2}+2 \mathrm{C}_{2} \mathrm{H}_{4}+\mathrm{OC}_{2} \mathrm{H}_{5}+\mathrm{e}$ & 5.241 \\
\hline nd14 & $\mathrm{Si}\left(\mathrm{OC}_{2} \mathrm{H}_{5}\right)_{4}+\mathrm{e} \rightarrow \mathrm{Si}\left(\mathrm{OC}_{2} \mathrm{H}_{5}\right)_{2} \mathrm{H}+\mathrm{OC}_{2} \mathrm{H}_{4}+\mathrm{OC}_{2} \mathrm{H}_{5}+\mathrm{e}$ & 5.893 \\
\hline nd15 & $\mathrm{Si}\left(\mathrm{OC}_{2} \mathrm{H}_{5}\right)_{4}+\mathrm{e} \rightarrow \mathrm{SiOH}+\mathrm{C}_{2} \mathrm{H}_{5}+\mathrm{OC}_{2} \mathrm{H}_{4}+2 \mathrm{OC}_{2} \mathrm{H}_{5}+\mathrm{e}$ & 10.776 \\
\hline nd16 & $\mathrm{Si}\left(\mathrm{OC}_{2} \mathrm{H}_{5}\right)_{4}+\mathrm{e} \rightarrow \mathrm{Si}(\mathrm{OH})_{2} \mathrm{H}+\mathrm{OC}_{2} \mathrm{H}_{4}+2 \mathrm{C}_{2} \mathrm{H}_{4}+\mathrm{OC}_{2} \mathrm{H}_{5}+\mathrm{e}$ & 6.679 \\
\hline nd17 & $\mathrm{Si}\left(\mathrm{OC}_{2} \mathrm{H}_{5}\right)_{4}+\mathrm{e} \rightarrow \mathrm{Si}\left(\mathrm{OC}_{2} \mathrm{H}_{5}\right)(\mathrm{OH}) \mathrm{H}+\mathrm{OC}_{2} \mathrm{H}_{4}+\mathrm{C}_{2} \mathrm{H}_{4}+\mathrm{OC}_{2} \mathrm{H}_{5}+\mathrm{e}$ & 6.280 \\
\hline nd18 & $\mathrm{Si}\left(\mathrm{OC}_{2} \mathrm{H}_{5}\right)_{4}+\mathrm{e} \rightarrow \mathrm{Si}(\mathrm{OH})_{3}+3 \mathrm{C}_{2} \mathrm{H}_{4}+\mathrm{OC}_{2} \mathrm{H}_{5}+\mathrm{e}$ & 5.591 \\
\hline
\end{tabular}


Table I. (continued)

\begin{tabular}{|c|c|c|}
\hline Label & Reaction & $\begin{array}{l}\Delta E_{i} \\
(\mathrm{eV})\end{array}$ \\
\hline i1 & $\mathrm{Si}\left(\mathrm{OC}_{2} \mathrm{H}_{5}\right)_{4}+\mathrm{e} \rightarrow \mathrm{Si}\left(\mathrm{OC}_{2} \mathrm{H}_{5}\right)\left(\mathrm{OCH}_{2}\right) \mathrm{H}_{2}^{+}+\mathrm{OC}_{2} \mathrm{H}_{4}+\mathrm{OC}_{2} \mathrm{H}_{5}+\mathrm{CH}_{2}+2 \mathrm{e}$ & 10.6 \\
\hline i2 & $\mathrm{Si}\left(\mathrm{OC}_{2} \mathrm{H}_{5}\right)_{4}+\mathrm{e} \rightarrow \mathrm{Si}\left(\mathrm{OC}_{2} \mathrm{H}_{5}\right)_{3} \mathrm{O}^{+}+\mathrm{C}_{2} \mathrm{H}_{5}+2 \mathrm{e}$ & 11.3 \\
\hline i3 & $\mathrm{Si}\left(\mathrm{OC}_{2} \mathrm{H}_{5}\right)_{4}+\mathrm{e} \rightarrow \mathrm{Si}\left(\mathrm{OC}_{2} \mathrm{H}_{5}\right)_{3} \mathrm{OC}_{2} \mathrm{H}_{4}^{+}+\mathrm{H}+2 \mathrm{e}$ & 11.4 \\
\hline i4 & $\mathrm{Si}\left(\mathrm{OC}_{2} \mathrm{H}_{5}\right)_{4}+\mathrm{e} \rightarrow \mathrm{OC}_{2} \mathrm{H}_{5}^{+}+\mathrm{Si}\left(\mathrm{OC}_{2} \mathrm{H}_{5}\right)_{3}+2 \mathrm{e}$ & 11.6 \\
\hline i5 & $\mathrm{Si}\left(\mathrm{OC}_{2} \mathrm{H}_{5}\right)_{4}+\mathrm{e} \rightarrow \mathrm{Si}\left(\mathrm{OC}_{2} \mathrm{H}_{5}\right)_{4}^{+}+2 \mathrm{e}$ & 11.6 \\
\hline i6 & $\mathrm{Si}\left(\mathrm{OC}_{2} \mathrm{H}_{5}\right)_{4}+\mathrm{e} \rightarrow \mathrm{Si}\left(\mathrm{OC}_{2} \mathrm{H}_{5}\right)_{2} \mathrm{O}(\mathrm{OH})^{+}+\mathrm{C}_{2} \mathrm{H}_{4}+\mathrm{C}_{2} \mathrm{H}_{5}+2 \mathrm{e}$ & 11.6 \\
\hline i7 & $\mathrm{Si}\left(\mathrm{OC}_{2} \mathrm{H}_{5}\right)_{4}+\mathrm{e} \rightarrow \mathrm{Si}\left(\mathrm{OC}_{2} \mathrm{H}_{5}\right)_{3}^{+}+\mathrm{OC}_{2} \mathrm{H}_{5}+2 \mathrm{e}$ & 11.6 \\
\hline i8 & $\mathrm{Si}\left(\mathrm{OC}_{2} \mathrm{H}_{5}\right)_{4}+\mathrm{e} \rightarrow \mathrm{Si}\left(\mathrm{OC}_{2} \mathrm{H}_{5}\right)_{3} \mathrm{OCH}_{2}^{+}+\mathrm{CH}_{3}+2 \mathrm{e}$ & 11.7 \\
\hline i9 & $\mathrm{Si}\left(\mathrm{OC}_{2} \mathrm{H}_{5}\right)_{4}+\mathrm{e} \rightarrow \mathrm{Si}\left(\mathrm{OC}_{2} \mathrm{H}_{5}\right)_{2}(\mathrm{OH})^{+}+\mathrm{C}_{2} \mathrm{H}_{4}+\mathrm{OC}_{2} \mathrm{H}_{5}+2 \mathrm{e}$ & 12.0 \\
\hline $\mathrm{i} 10$ & $\mathrm{Si}\left(\mathrm{OC}_{2} \mathrm{H}_{5}\right)_{4}+\mathrm{e} \rightarrow \mathrm{OCH}_{3}^{+}+\mathrm{Si}\left(\mathrm{OC}_{2} \mathrm{H}_{5}\right)_{3} \mathrm{CH}_{2}+2 \mathrm{e}$ & 12.0 \\
\hline i11 & $\mathrm{Si}\left(\mathrm{OC}_{2} \mathrm{H}_{5}\right)_{4}+\mathrm{e} \rightarrow \mathrm{Si}\left(\mathrm{OC}_{2} \mathrm{H}_{5}\right)\left(\mathrm{OCH}_{2}\right)(\mathrm{OH})_{2}^{+}+2 \mathrm{C}_{2} \mathrm{H}_{4}+\mathrm{CH}_{3}+2 \mathrm{e}$ & 12.2 \\
\hline $\mathrm{i} 12$ & $\mathrm{Si}\left(\mathrm{OC}_{2} \mathrm{H}_{5}\right)_{4}+\mathrm{e} \rightarrow \mathrm{Si}\left(\mathrm{OC}_{2} \mathrm{H}_{5}\right)_{2}\left(\mathrm{OCH}_{2}\right)(\mathrm{OH})^{+}+\mathrm{C}_{2} \mathrm{H}_{4}+\mathrm{CH}_{3}+2 \mathrm{e}$ & 12.2 \\
\hline $\mathrm{i} 13$ & $\mathrm{Si}\left(\mathrm{OC}_{2} \mathrm{H}_{5}\right)_{4}+\mathrm{e} \rightarrow \mathrm{Si}\left(\mathrm{OC}_{2} \mathrm{H}_{5}\right)_{2}\left(\mathrm{OCH}_{2}\right) \mathrm{H}^{+}+\mathrm{OC}_{2} \mathrm{H}_{4}+\mathrm{CH}_{3}+2 \mathrm{e}$ & 12.2 \\
\hline i14 & $\mathrm{Si}\left(\mathrm{OC}_{2} \mathrm{H}_{5}\right)_{4}+\mathrm{e} \rightarrow \mathrm{Si}\left(\mathrm{OC}_{2} \mathrm{H}_{5}\right)\left(\mathrm{OCH}_{2}\right)(\mathrm{OH}) \mathrm{H}^{+}+\mathrm{OC}_{2} \mathrm{H}_{4}+\mathrm{C}_{2} \mathrm{H}_{4}+\mathrm{CH}_{3}+2 \mathrm{e}$ & 12.3 \\
\hline i15 & $\mathrm{Si}\left(\mathrm{OC}_{2} \mathrm{H}_{5}\right)_{4}+\mathrm{e} \rightarrow \mathrm{Si}\left(\mathrm{OC}_{2} \mathrm{H}_{5}\right)(\mathrm{OH})_{2}{ }^{+}+2 \mathrm{C}_{2} \mathrm{H}_{4}+\mathrm{OC}_{2} \mathrm{H}_{5}+2 \mathrm{e}$ & 12.7 \\
\hline i16 & $\mathrm{Si}\left(\mathrm{OC}_{2} \mathrm{H}_{5}\right)_{4}+\mathrm{e} \rightarrow \mathrm{Si}\left(\mathrm{OC}_{2} \mathrm{H}_{5}\right)_{2} \mathrm{H}^{+}+\mathrm{OC}_{2} \mathrm{H}_{4}+\mathrm{OC}_{2} \mathrm{H}_{5}+2 \mathrm{e}$ & 13.4 \\
\hline i17 & $\mathrm{Si}\left(\mathrm{OC}_{2} \mathrm{H}_{5}\right)_{4}+\mathrm{e} \rightarrow \mathrm{SiOH}^{+}+\mathrm{C}_{2} \mathrm{H}_{4}+3 \mathrm{OC}_{2} \mathrm{H}_{5}+2 \mathrm{e}$ & 14.7 \\
\hline i18 & $\mathrm{Si}\left(\mathrm{OC}_{2} \mathrm{H}_{5}\right)_{4}+\mathrm{e} \rightarrow \mathrm{Si}(\mathrm{OH})_{2} \mathrm{H}^{+}+\mathrm{OC}_{2} \mathrm{H}_{4}+2 \mathrm{C}_{2} \mathrm{H}_{4}+\mathrm{OC}_{2} \mathrm{H}_{5}+2 \mathrm{e}$ & 15.1 \\
\hline i19 & $\mathrm{Si}\left(\mathrm{OC}_{2} \mathrm{H}_{5}\right)_{4}+\mathrm{e} \rightarrow \mathrm{Si}\left(\mathrm{OC}_{2} \mathrm{H}_{5}\right)(\mathrm{OH}) \mathrm{H}^{+}+\mathrm{OC}_{2} \mathrm{H}_{4}+\mathrm{C}_{2} \mathrm{H}_{4}+\mathrm{OC}_{2} \mathrm{H}_{5}+2 \mathrm{e}$ & 15.4 \\
\hline i20 & $\mathrm{Si}\left(\mathrm{OC}_{2} \mathrm{H}_{5}\right)_{4}+\mathrm{e} \rightarrow \mathrm{Si}(\mathrm{OH})_{3}{ }^{+}+3 \mathrm{C}_{2} \mathrm{H}_{4}+\mathrm{OC}_{2} \mathrm{H}_{5}+2 \mathrm{e}$ & 16.0 \\
\hline
\end{tabular}




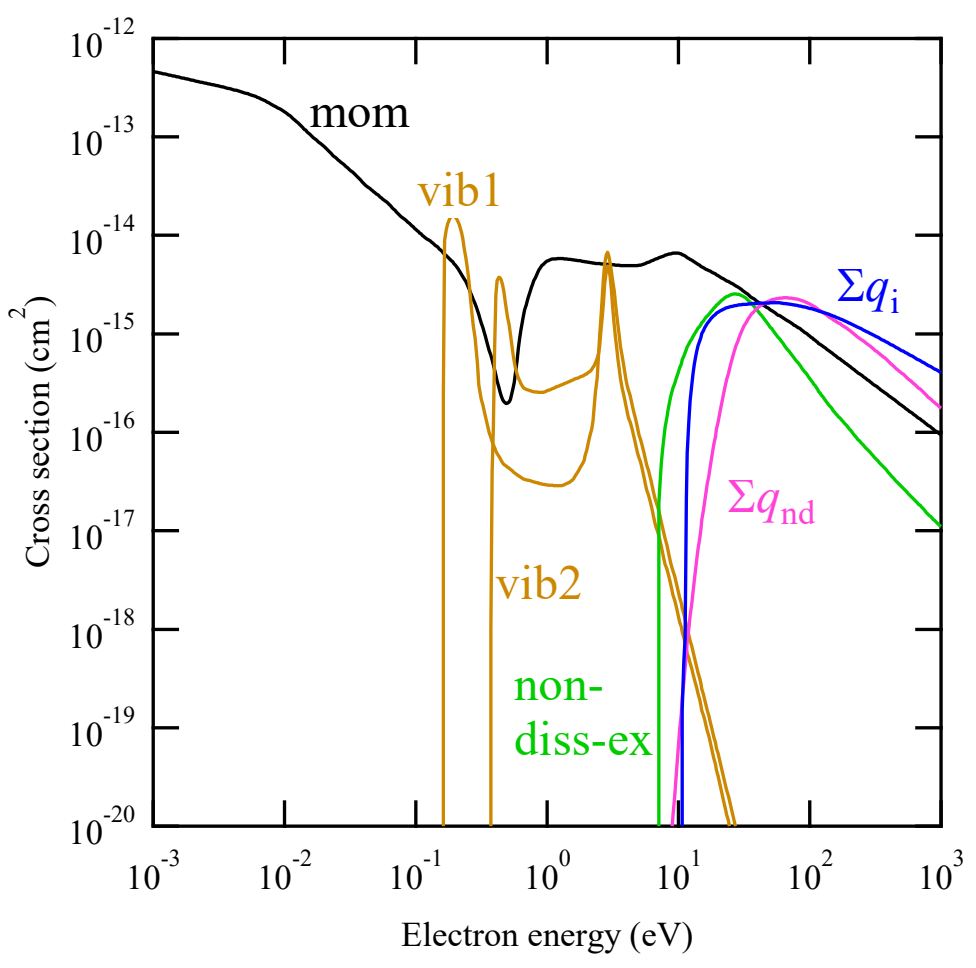

Fig. 1. (Color Online) 


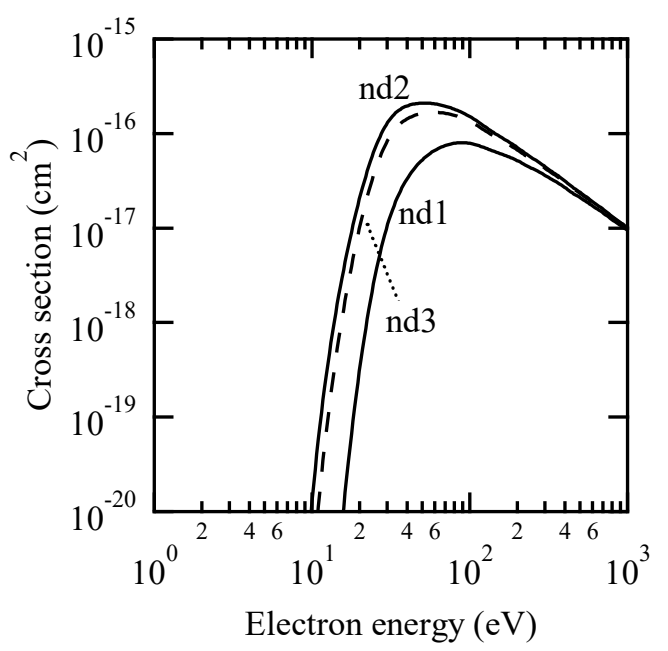

(a)

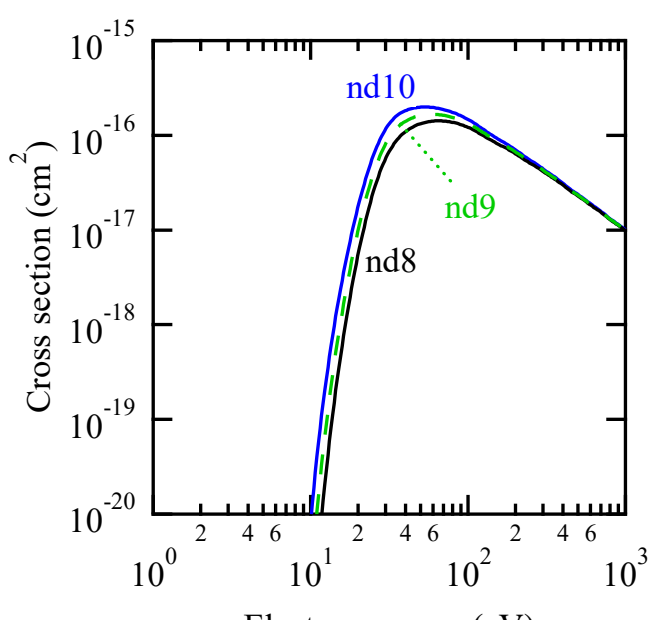

Electron energy $(\mathrm{eV})$

(c)

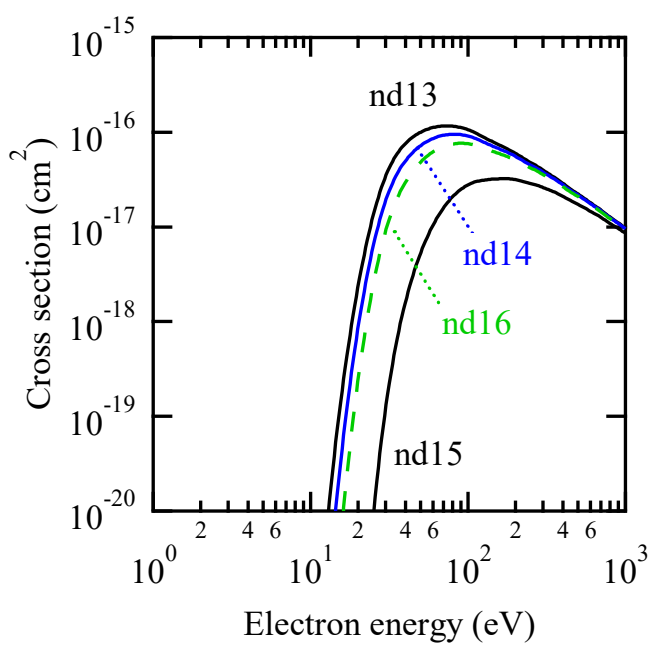

(e)

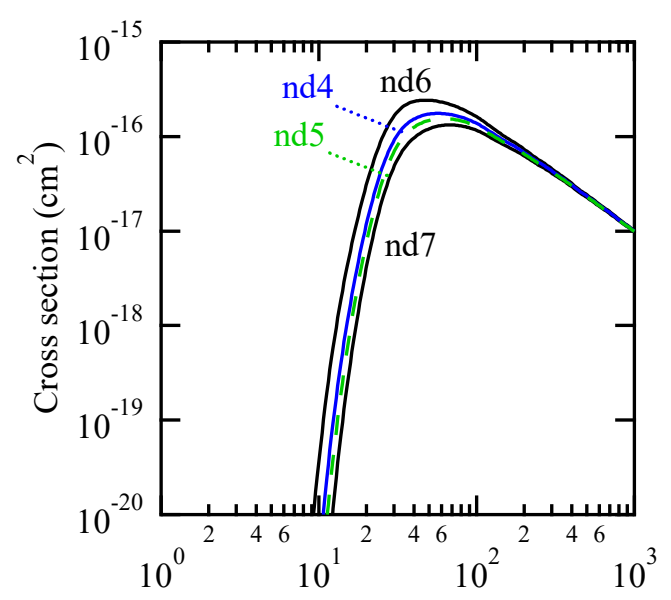

Electron energy (eV)

(b)

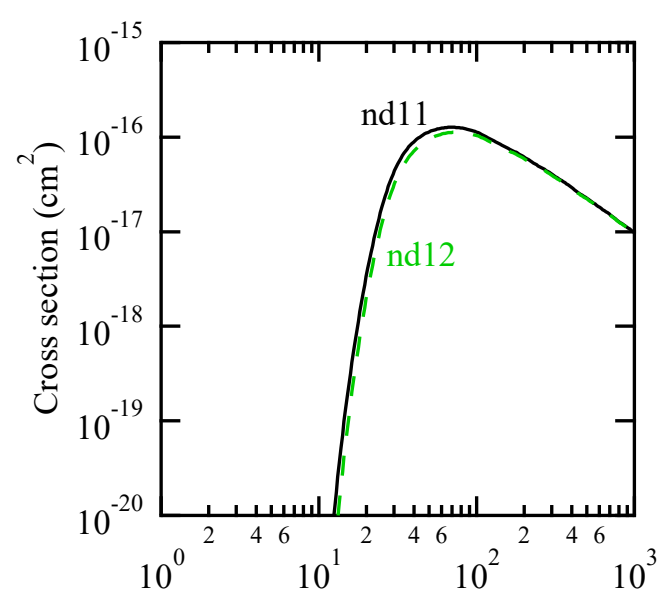

Electron energy $(\mathrm{eV})$

(d)

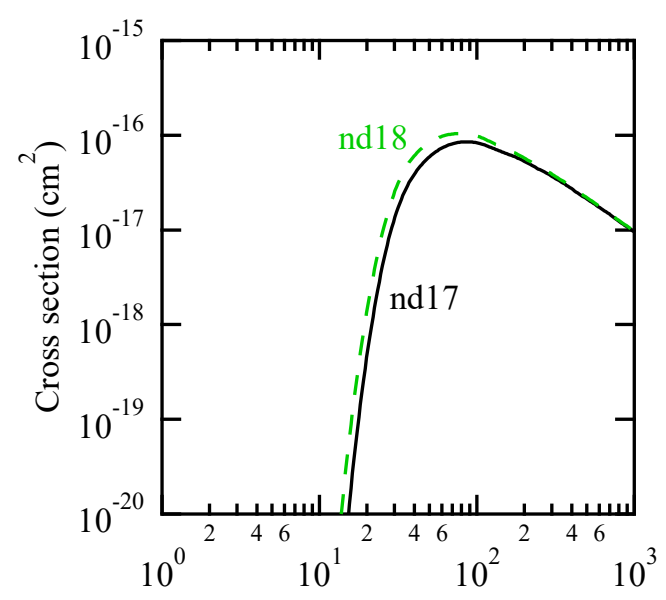

Electron energy $(\mathrm{eV})$

(f)

Fig. 2. (Color Online) 


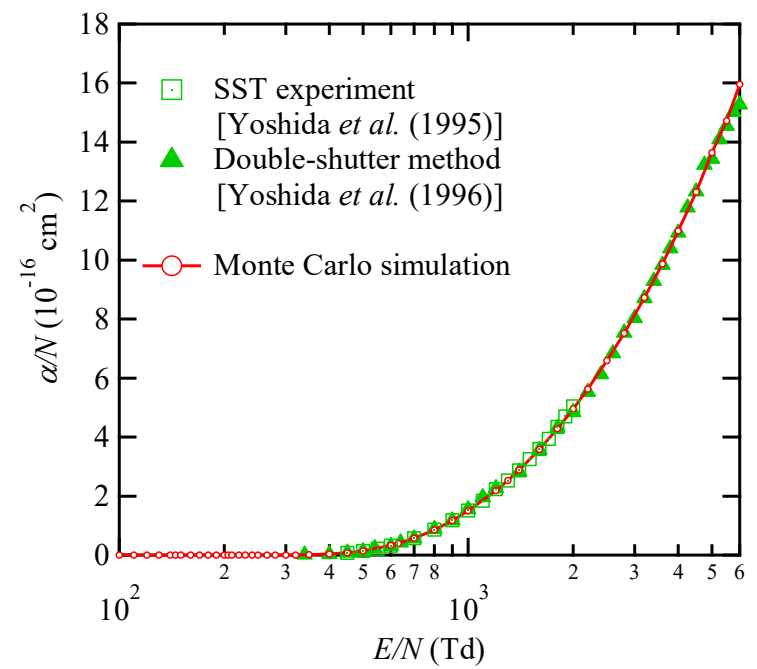

(a)

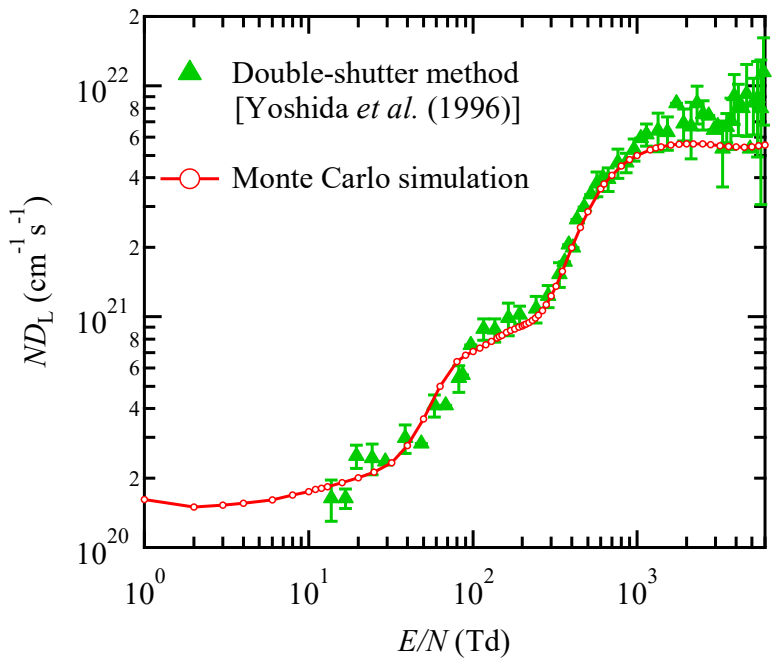

(b)

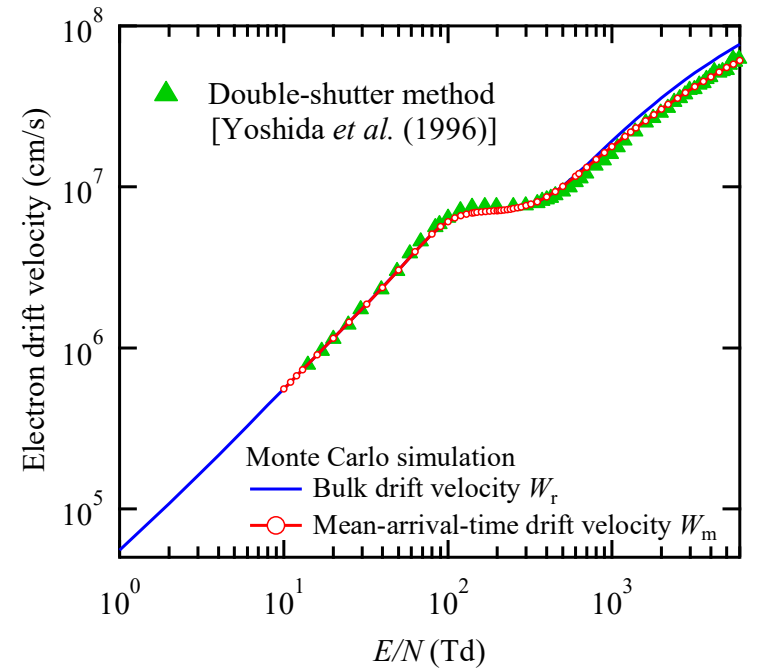

(c)

Fig. 3. (Color Online) 


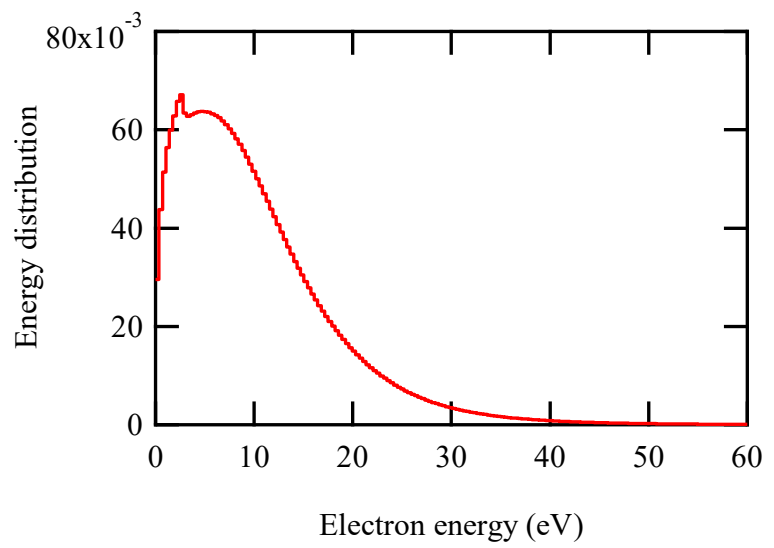

Fig. 4. (Color Online) 


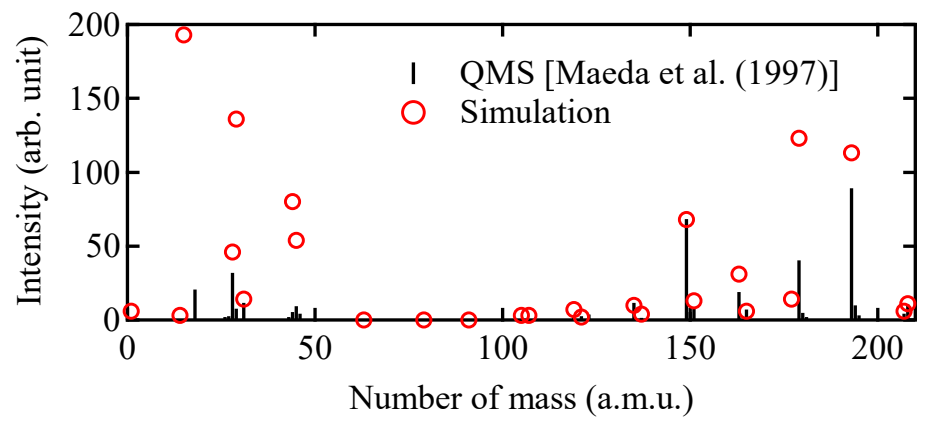

(a)

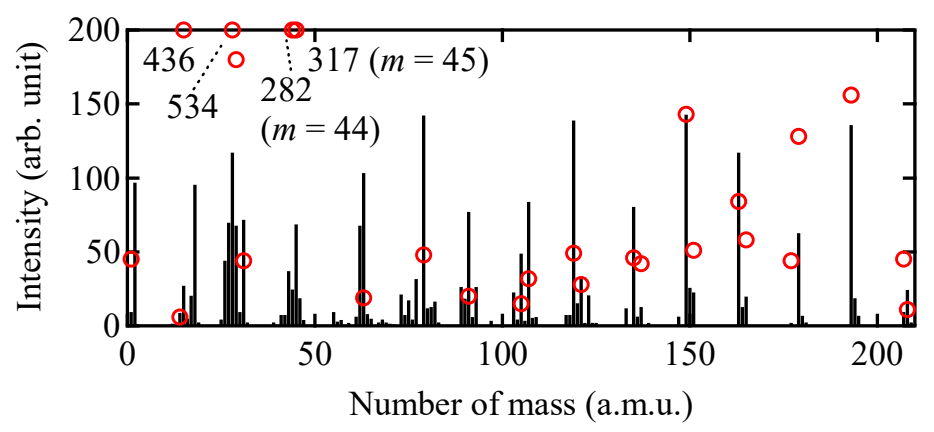

(b)

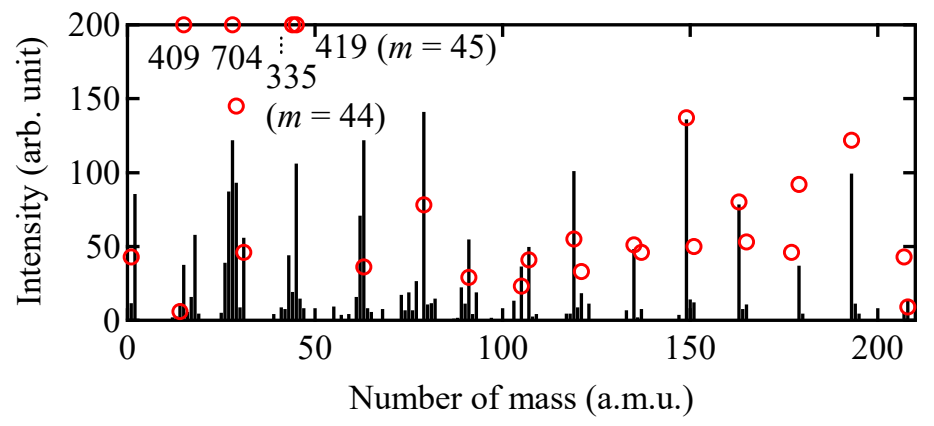

(c)

Fig. 5. (Color Online) 


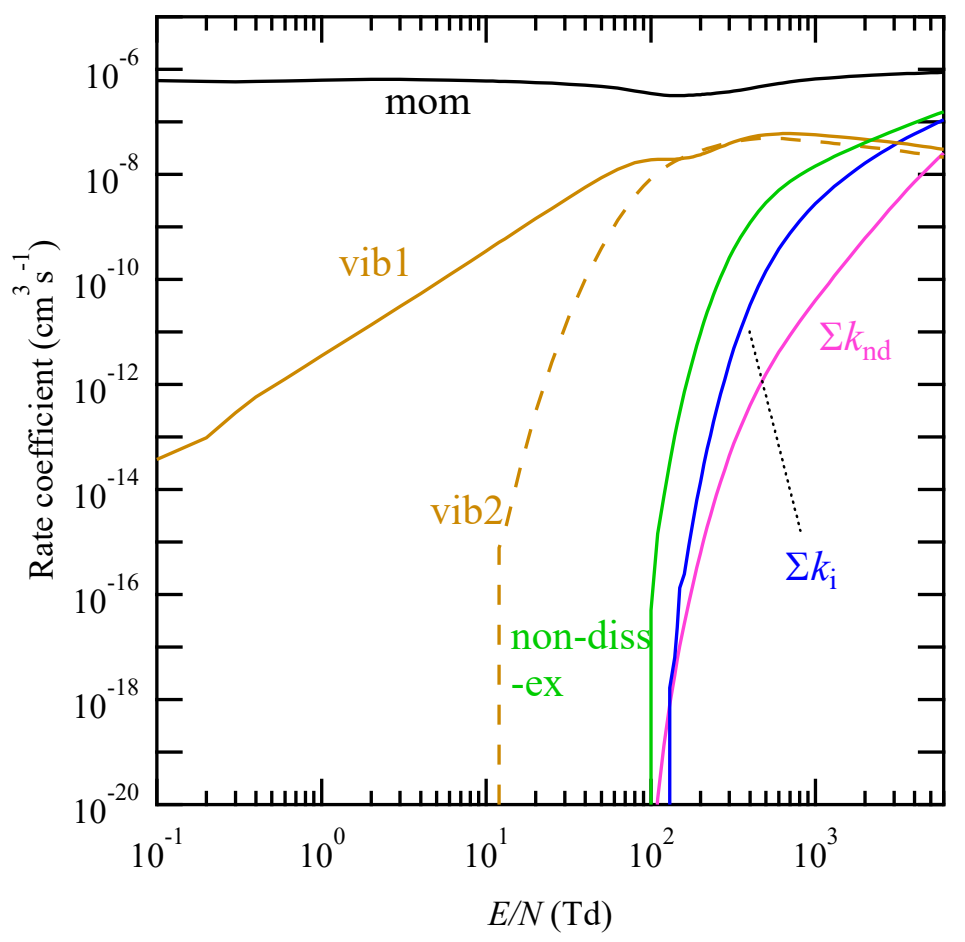

Fig. 6 (Color Online) 


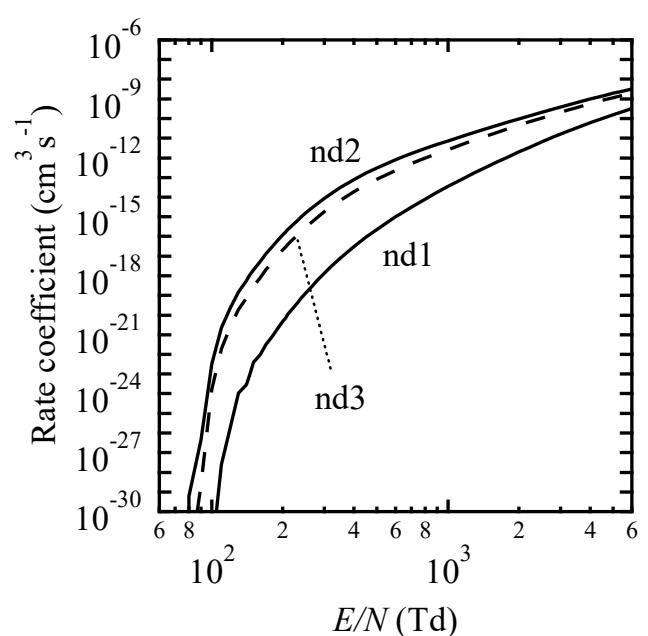

(a)

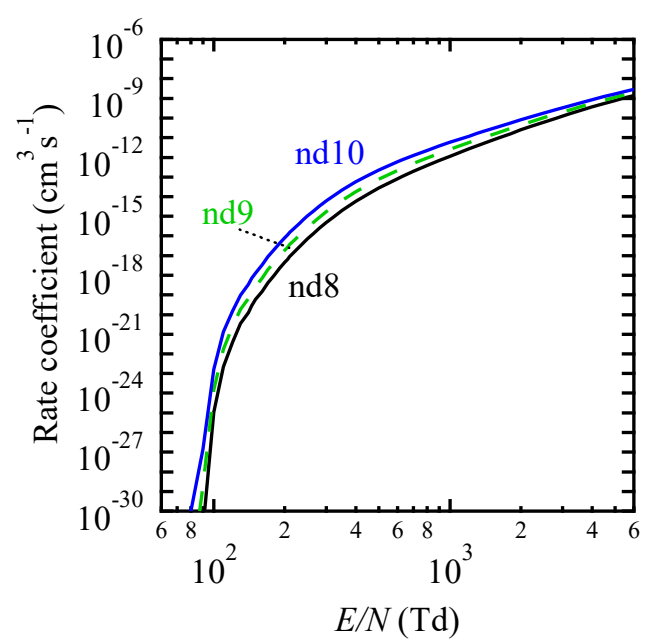

(c)

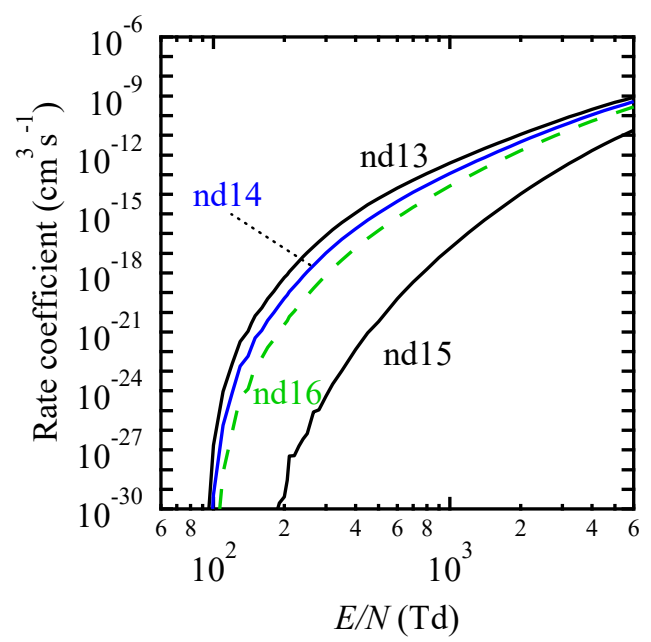

(e)

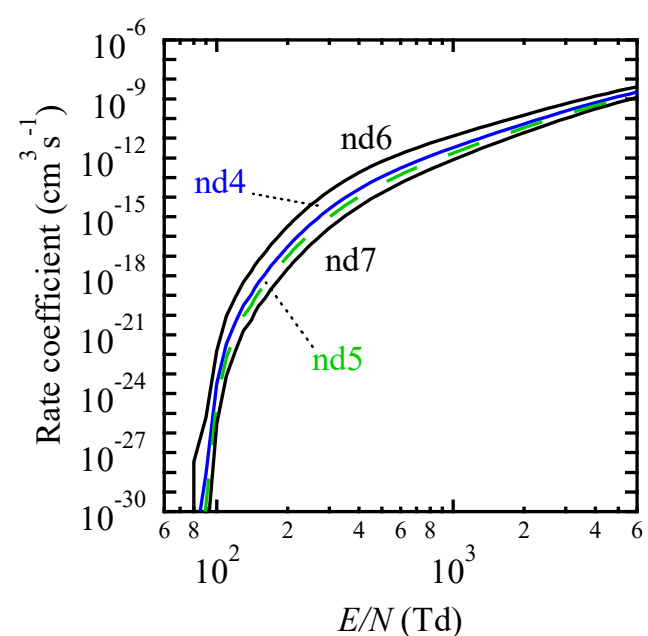

(b)

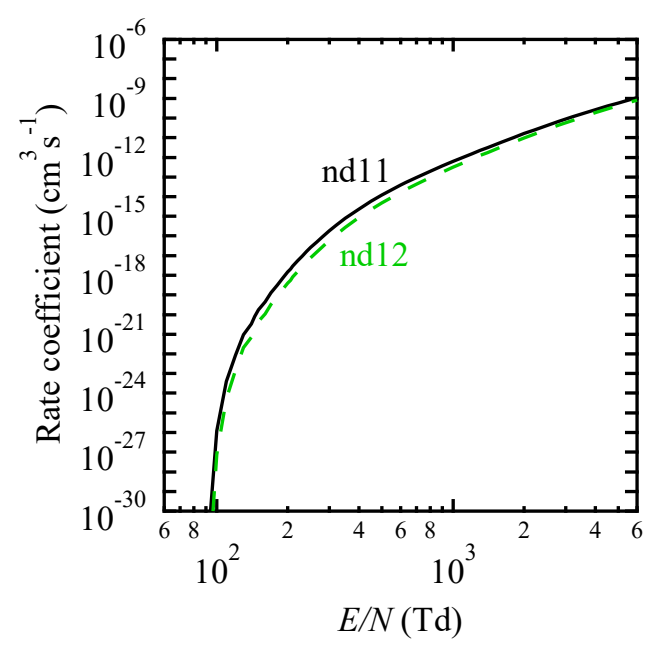

(d)

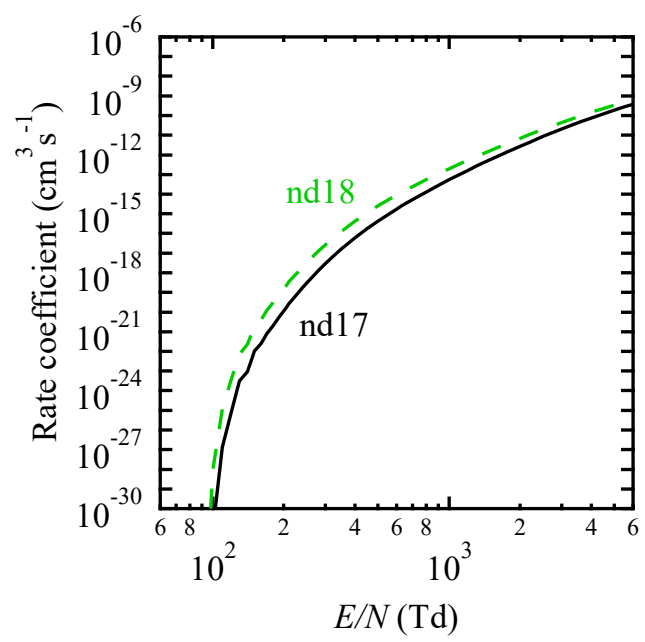

(f)

Fig. 7. (Color Online) 


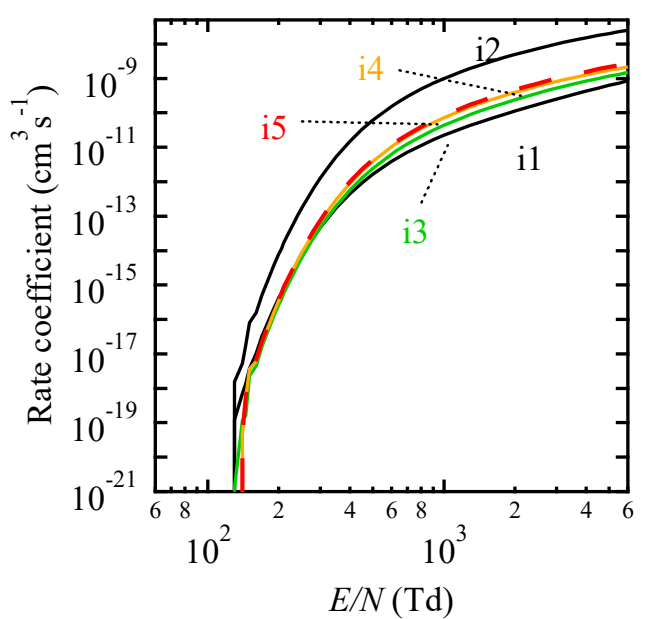

(a)

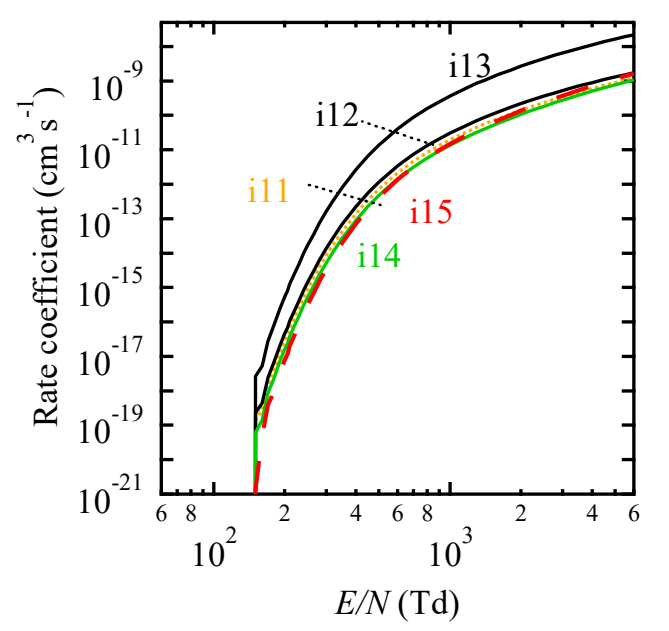

(c)

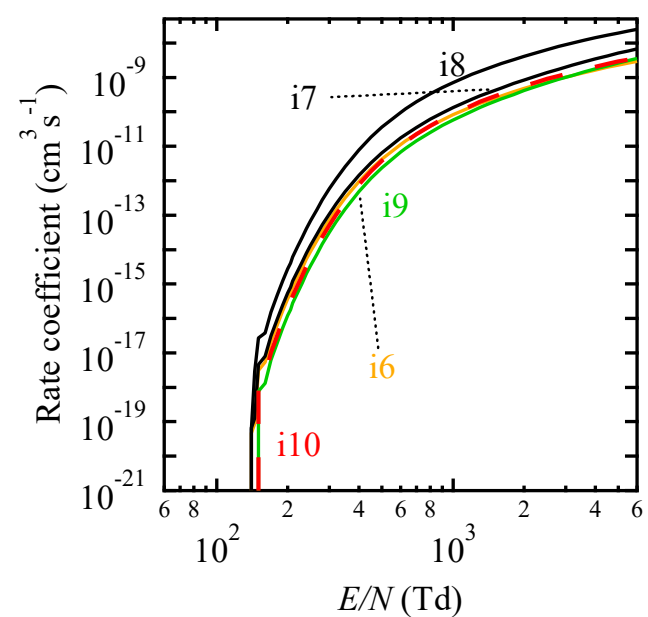

(b)

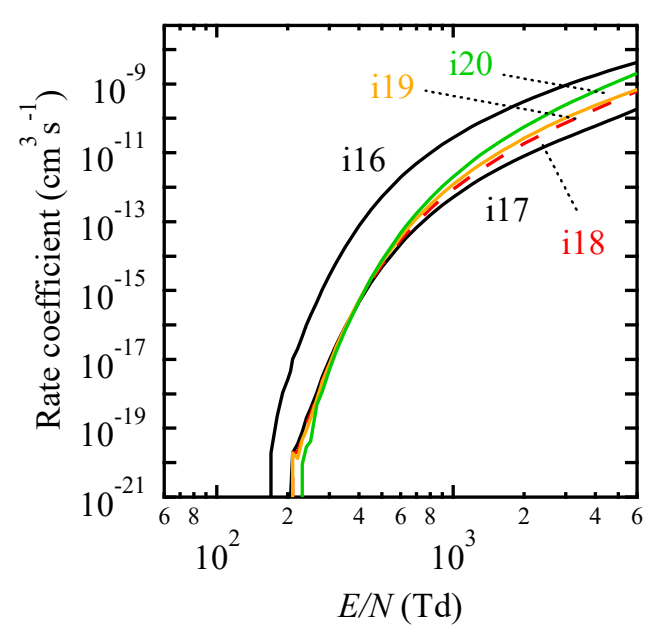

(d)

Fig. 8. (Color Online) 